\title{
URBAN GEOGRAPHY AND COMPLEXITY
}

\author{
Denise Pumain \\ University Paris Panthéon-Sorbonne, 13 rue du Four, 75006 Paris, France \\ e-mail: pumain@parisgeo.cnrs.fr
}

\begin{abstract}
The contemporary approach of complex systems raises common questions that could be handled by a transdisciplinary theory. We demonstrate how the main concepts of urban geography could be integrated in such a theory ofcomplexity. We illustrate the complexity approach by a short presentationof the SIMPOP model that uses a multi-agents formalism for the simulationof the evolutionary properties of systems of cities.
\end{abstract}

Key words: system of cities, urban geography, complex system, complexity 